\title{
Detection limits of the strip test and PCR for genetically modified corn in Brazil
}

\author{
V.E. Nascimento, É.V.R. Von Pinho, R.G. Von Pinho and \\ A.D. do Nascimento Júnior \\ Departamento Agricultura, Universidade Federal de Lavras, \\ Lavras, MG, Brasil \\ Corresponding author: V.E. Nascimento \\ E-mail: vivian_nascimento@hotmail.com
}

Genet. Mol. Res. 11 (3): 2497-2505 (2012)

Received October 7, 2011

Accepted May 10, 2012

Published June 27, 2012

DOI http://dx.doi.org/10.4238/2012.June.27.2

\begin{abstract}
Brazilian legislation establishes a labeling limit for products that contain more than $1 \%$ material from genetically modified organisms (GMOs). We assessed the sensitivity of the lateral flow strip test in detection of the GMO corn varieties Bt11 and MON810 and the specificity and sensitivity of PCR techniques for their detection. For the strip test, the GMO seeds were mixed with conventional seeds at levels of $0.2,0.4$ and $0.8 \%$ for Bt11, and $0.4,0.8$ and $1.6 \%$ for MON810. Three different methodologies were assessed and whole seeds, their endosperm and embryonic axis were used. For the PCR technique, the GMO seeds of each of the two varieties were mixed with conventional seeds at levels of 20, 10, 5, 2, 1, and $0.5 \%$. The seeds were ground and the DNA extracted. For detection of the GMO material, specific primers were used for MON810 and Bt11 and maize zein as an endogenous control. The sensitivity of the strip test varied for both maize varieties and methodologies. The test was positive for Bt11 only at $0.8 \%$, in contrast with the detection limit of $0.4 \%$ indicated by the manufacturer. In the multiplex PCR, the primers proved to be specific for the different varieties. These varieties were detected in samples with one GMO seed in 100. Thus, this technique proved to be efficient in detecting
\end{abstract}


contaminations equal to or greater than $1 \%$.

Key words: Strip test; PCR; Genetically modified organism

\section{INTRODUCTION}

In 2010, Brazil was second in the world in relation to genetically modified (GM) crop area, this being estimated at 25.4 million hectares, 7.3 million hectares of which were planted with genetically modified corn resistant to insects (James, 2009).

In view of this scenario of increasing genetically modified crop area, the labeling and traceability of these products are current questions when considering trade and regulation. Accordingly, tests for the detection of genetically modified organisms (GMOs) in plants and foods are essential tools for farmers, food producers, retailers, and regulatory agencies. This owes to the fact that in practically the entire world, laws and consumer demand require the GMO content in foods to be verified before they are imported or placed on the market. In addition to legal aspects, the certification of genetic purity in seeds and grains is fundamental in quality control programs.

Various methods have been developed for detecting and identifying specific events of genetic modification. Understanding the operation of diagnostic tests allows the reduction in the number of false positive and false negative results that may occur during the performance of tests on lots of seeds and grains. In general, these methods may be classified into two categories. The first category includes methods that require the amplification of a DNA segment with subsequent direct or indirect detection of the final product, and the second includes methods that involve protein detection with the use of labeled antibodies (Ahmed, 2002).

The PCR technique, which consists of the selective amplification of specific DNA sequences, is the main method used for the detection and quantification of GMOs. In this case, PCR amplifies a segment of gene construction inserted in the plant. Although the method has some limitations, its high sensitivity, specificity, and capacity for detecting a broad series of events and distinguishing the genetically modified varieties that have different gene constructions explain why it has been chosen for assessing the detection of GMOs and their derivatives.

Despite that immunological and PCR methods differ in regard to sensitivity, speed and cost of analysis, there is broad agreement between the results obtained with the two types of methods. Nevertheless, the strength of the method, the need for a quick qualitative response, the speed of execution, the legal limits and training of personnel may define the choice in favor of quick immunological methods, principally those in simpler configuration, such as the strip method. Still, factors that may interfere with the results of the assessments must be evaluated. It is known that there are different levels of expression of proteins in seeds depending on the biotechnological event and that these levels also vary in the seed structures.

In corn, the seed tissues have different ploidy levels. The embryo is $2 \mathrm{n}$, with half coming from the male parental line and half from the female parental line; the endosperm is $3 \mathrm{n}$, in which $2 \mathrm{n}$ comes from the female and $1 \mathrm{n}$ from the male; and the seed coat is $2 \mathrm{n}$, with maternal tissue being derived from the ovule. Therefore, this difference may have an influence on the detection of the event in terms of the parental line in which the event was introduced (International Seed Testing Association - ISTA, 2009).

In this perspective, the purpose of this study was to assess the sensitivity of the strip test in detecting the events Bt11 and MON810, with resistance to insects, in different tissues 
of corn seed, and also to assess the specificity and sensitivity of the multiplex PCR technique in detection of the genetically modified corn events MON810 and Bt11.

\section{MATERIAL AND METHODS}

\section{Location for carrying out the experiment}

The experiment was carried out at the Central Seed Laboratory of the Agriculture Department of the Universidade Federal de Lavras (UFLA), in Lavras, MG, Brazil.

\section{Lateral flow strip test}

Seeds of the commercial corn cultivars DKB 390 conventional, Yieldgard (MON810) and Maximus TL (Bt11) were used.

For the purpose of simulating different levels of contamination, genetically modified seeds (Yieldgard and TL) were mixed with the conventional seeds in proportions of 0.2, 0.4 and $0.8 \%$ for Bt11, and $0.4,0.8$ and $1.6 \%$ for MON810. These proportions were defined based on the specifications of the commercial kit, Gehaka ${ }^{\circledR}$ brand, with detection limit of 0.4 and $0.8 \%$ for the events Bt11 and MON810, respectively. In this test, three different methodologies were assessed.

In the first methodology, whole seeds, endosperm and embryonic axis were used for 500 seeds (equivalent to $160 \mathrm{~g}$, recommended by the kit). The materials were ground for $30 \mathrm{~s}$ in a blender, and afterwards, $200 \mathrm{~mL}$ sample dilution buffer were added. To proceed with the test, $0.5 \mathrm{~mL}$ ground extract was pipetted and placed in a $1.5-\mathrm{mL}$ tube in the presence of the strip containing the antibodies.

In a second methodology, whole seeds, endosperm and embryonic axis were used for 500 seeds (equivalent to $160 \mathrm{~g}$ ). After separating the endosperms and the embryonic axis of the seeds, they were ground and weighed. The weight of the embryonic axis was used as a reference for all the other treatments. Afterwards, the buffer was added for sampling, diluted in proportion to the weight of the embryonic axis. To proceed with the test, $0.5 \mathrm{~mL}$ ground extract was pipetted and placed in a $1.5-\mathrm{mL}$ tube in the presence of the strip.

In a third methodology, whole seeds, endosperm and embryonic axis were used for 500 seeds (equivalent to $160 \mathrm{~g}$ ). The materials were ground for $30 \mathrm{~s}$ in a blender, and afterwards, buffer for sampling was added, diluted in proportion to the weight of each material. To proceed with the test, $0.5 \mathrm{~mL}$ ground extract was pipetted and placed in a $1.5-\mathrm{mL}$ tube in the presence of the strip.

The strips were read after $10 \mathrm{~min}$. For each methodology, a positive control with genetically modified seeds and a negative control with conventional seeds were included.

\section{Multiplex PCR}

For assessment of the specificity of the technique in detecting the events MON810 and Bt11, seeds of the commercial corn hybrids DKB 390 conventional and TC1507 (Herculex event) were used as negative control.

For the purpose of simulating different levels of contamination, genetically modified seeds (MON810 and Bt11) were mixed with conventional seeds in proportions of 1 in $5(20 \%)$, 
1 in $10(10 \%), 1$ in $20(5 \%), 1$ in $50(2 \%), 1$ in $100(1 \%)$, and 1 in $200(0.5 \%)$ for both events. Seeds of each mixture were ground in a cooled mill, and afterwards, DNA was extracted. For extraction, $620 \mu \mathrm{L} \mathrm{2 \%} \mathrm{CTAB} \mathrm{extraction} \mathrm{buffer} \mathrm{(2 \%} \mathrm{CTAB;} 1 \mathrm{M}$ Tris- $\mathrm{HCl}$, $\mathrm{pH} 7.5$; $0.5 \mathrm{mM}$ EDTA, $\mathrm{pH} 8.0 ; 5 \mathrm{M} \mathrm{NaCl}$ ) were added to $50 \mathrm{mg}$ macerated sample, along with $2 \% \beta$ mercaptoethanol, and the mixture was incubated at $65^{\circ} \mathrm{C}$ for $60 \mathrm{~min}$. At the end of this period, $350 \mu \mathrm{L}$ chloroform-isoamyl alcohol mixture (24:1) was added, and the mixture was lightly stirred for $5 \mathrm{~min}$ so as to obtain an emulsion, which was then centrifuged at 14,000 rpm for $10 \mathrm{~min}$. The supernatant was transferred to a new tube and the previous procedure was repeated. Next, ice-cold isopropanol was added in the proportion of 1:1, and the mixture was centrifuged at $14,000 \mathrm{rpm}$ for 6 min and the pellet washed with 70\% ethanol. After drying at ambient temperature, the DNA was resuspended in $50 \mu \mathrm{L}$ ultrapure water. At the end of extraction, $2 \mu \mathrm{L}$ RNAse were added, followed by incubation at $37^{\circ} \mathrm{C}$, for $2 \mathrm{~h}$. Quantification of the DNA was assessed by the absorbance method at $260 \mathrm{~nm}$ in a spectrophotometer (NanoVue-GE Healthcare) and on a $0.8 \%$ agarose gel.

For qualitative detection of the genetically modified event, the PCR was performed using specific primers for the events MON810 and Bt11 and the zein gene as endogenous control (Table 1).

PCRs consisted of $100 \mathrm{ng}$ DNA, $0.2 \mu \mathrm{M}$ each primer, $0.2 \mu \mathrm{M}$ dNTPs, $50 \mathrm{mM} \mathrm{MgCl}{ }_{2}$ and 2.5 U Taq polymerase enzyme, in a total volume of $25 \mu \mathrm{L}$. Amplifications were carried out with an initial denaturation stage of $95^{\circ} \mathrm{C}$ for $5 \mathrm{~min}$, followed by 39 cycles of $95^{\circ} \mathrm{C}$ for 20 $\mathrm{s}, 58^{\circ} \mathrm{C}$ for $30 \mathrm{~s}$ and $72^{\circ} \mathrm{C}$ for $30 \mathrm{~s}$, along with final stage of $72^{\circ} \mathrm{C}$ for $5 \mathrm{~min}$.

Table 1. List of primers used in the PCR system (UFLA, Lavras, MG, 2010).

\begin{tabular}{|c|c|c|c|}
\hline Primer & Name & Sequence & bp \\
\hline MON810 corn & HS01-cry & AGT TTC CTT TTT GTT GCT CTC CT & 197 \\
\hline Bt11 corn & $\begin{array}{l}\text { BT11 1-5 } \\
\text { CRYIA } 1-3\end{array}$ & $\begin{array}{l}\text { CCA TTT TTC AGC TAG GAA GTT C } \\
\text { TCG TTG ATG TTK GGG TTG TTG TCC }\end{array}$ & 110 \\
\hline Zeina corn & $\begin{array}{l}\text { Zel 1-5, } \\
\text { Zel 1-3, }\end{array}$ & $\begin{array}{l}C C T C A G T C G \text { TAC ATA TCT ACT ATA CT } \\
\text { CTA GAA TGC AGC ACC AAC AAA }\end{array}$ & 508 \\
\hline
\end{tabular}

\section{RESULTS}

\section{Strip test}

The results presented in Tables 2, 3 and 4 show that the sensitivity of the strip test was different for the two events, treatments and methodologies used.

According to manufacturer specifications, considering the limit of detection of the kit used, $0.8 \%$ for MON 810 and $0.4 \%$ for Bt11 by methodology I, it was not possible to detect the event in whole seeds and embryonic axes for MON810, and in none of the materials used for Bt11. The test was positive for endosperm at the limit of $0.8 \%$ for MON810, which indicates that the gene was probably introduced in the female parental line. It should be noted that corn seeds mainly consist of endosperm tissue. Using this methodology, the test was positive for the event Bt11 only at the level of $0.8 \%$, which does not validate the detection of $0.4 \%$ indicated by the manufacturer. In this case, the result would be a false negative.

In methodologies II and III (Table 3 and 4), all the tests were positive with the use of the embryonic axis in all the treatments. In the first methodology, the embryonic axes were removed 
from $160 \mathrm{~g}$ of seeds, resulting in approximately $24 \mathrm{~g}$ of this material, to which $200 \mathrm{~mL}$ buffer were added. The solution was thus diluted more, compromising detection of the protein. Nevertheless, it should be pointed out that in the strip test, whole seeds are used and that in methodologies II and III, there was detection of the events MON810 and Bt11, with 1.6 and $0.8 \%$ contamination, respectively, coinciding with the results obtained with the use of methodology I.

Table 2. Results of the strip tests using methodology I (UFLA, Lavras, MG, 2010).

\begin{tabular}{|c|c|c|c|c|c|c|}
\hline Treatment & MON810: $1.6 \%$ & $0.8 \% *$ & $0.4 \%$ & Bt11: 0.8\% & $0.4 \% *$ & $0.2 \%$ \\
\hline Whole seed & + & - & - & + & - & - \\
\hline Endosperm & + & + & - & + & - & - \\
\hline Embryonic axis & - & - & - & + & - & - \\
\hline
\end{tabular}

*Detection limit for the event according to the technical specifications of the kit.

Table 3. Results of the strip tests using methodology II (UFLA, Lavras, MG, 2010).

\begin{tabular}{lcccccc}
\hline Treatment & MON810: $1.6 \%$ & $0.8 \% *$ & $0.4 \%$ & Bt11: $0.8 \%$ & $0.4 \% *$ \\
\hline Whole seed & + & - & - & + & - & $0.2 \%$ \\
Endosperm & + & + & - & + & + \\
Embryonic axis & + & + & + & + & + \\
\hline
\end{tabular}

*Detection limit for the event according to the technical specifications of the kit.

Table 4. Results of the strip tests using methodology III (UFLA, Lavras, MG, 2010).

\begin{tabular}{lcccccc}
\hline Treatment & MON810: $1.6 \%$ & $0.8 \% *$ & $0.4 \%$ & Bt11: $0.8 \%$ & $0.4 \% *$ & $0.2 \%$ \\
\hline Whole seed & + & - & - & + & - & - \\
Endosperm & + & + & + & + & + & + \\
Embryonic axis & + & + & + & + & + \\
\hline
\end{tabular}

*Detection limit for the event according to the technical specifications of the kit.

The results obtained in methodology III only differed from methodology II in the test for MON810 at the level of $0.4 \%$, which was also positive for the endosperm (Figure 1). That probably occurred because a large part of the sample is discarded in methodology II, increasing the probability of obtaining false negative results. Therefore, it may be affirmed that in methodology III greater efficiency was observed in the detection of the events in the different parts of the seed and that the quantity of buffer added to the samples may influence the results. Nevertheless, with the use of whole seeds, there was no variation in results between the methodologies used.

\section{Multiplex PCR}

The yield of the DNA extracted ranged from 300 to $1500 \mathrm{ng} / \mu \mathrm{L}$ for the corn samples. There was amplification of the zein gene for all the corn samples assessed, indicating good efficiency of the primer used as endogenous control and favorable conditions for analysis.

The primers used proved to be specific for the different events assessed in the multiplex PCR. As shown in Figure 2, in spite of the events Bt11 and MON810 having the same truncated gene $C r y 1 A b$, they showed different band patterns and absence of the Herculex event, which displays the gene Crylf. 

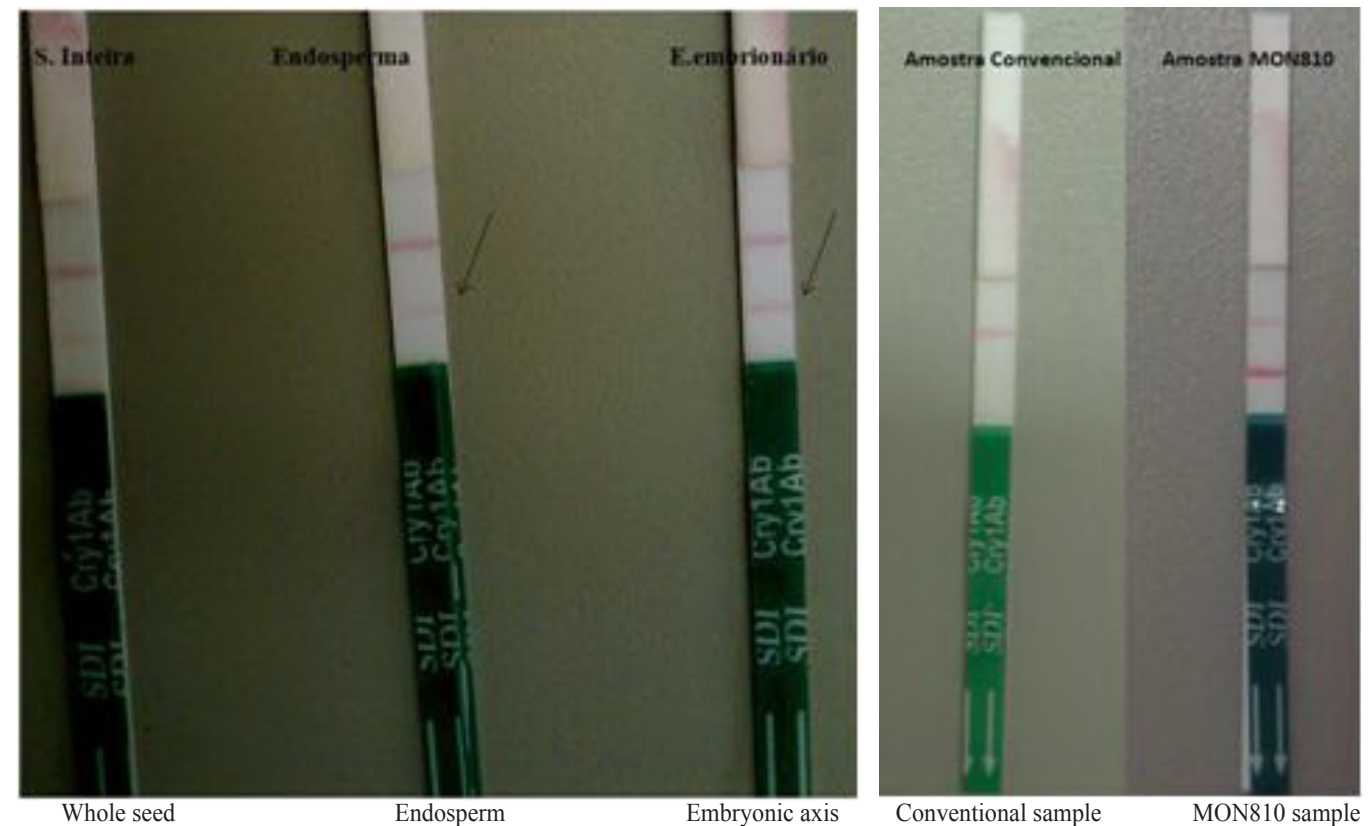

Figure 1. Results of the strip test for MON810, level of $0.8 \%$, methodology III. Conventional sample, negative control and MON810 sample, positive control.

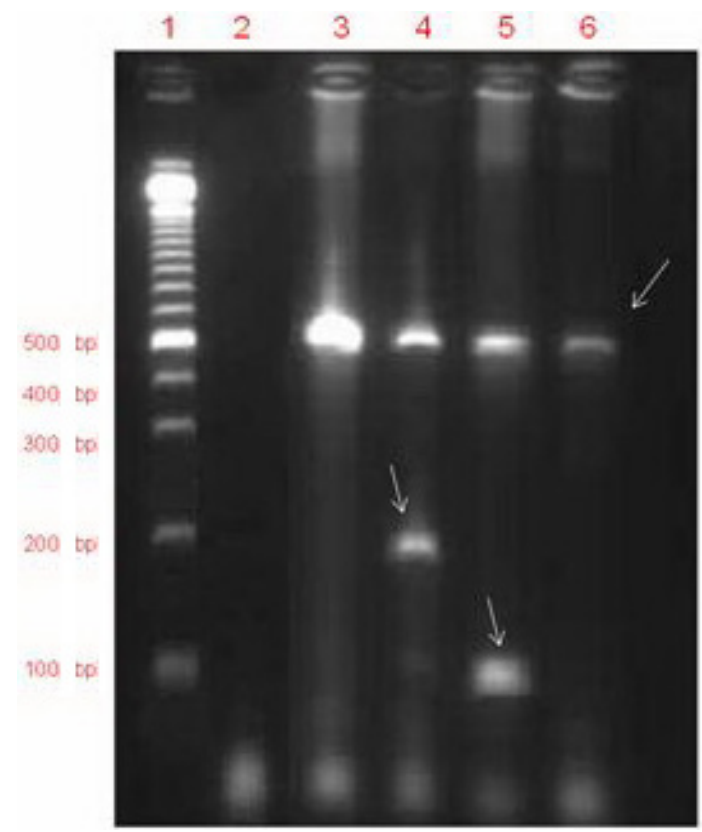

Figure 2. Results of specificity of multiplex PCR for the events Bt11 and MON810 and zein gene. Lanes 1-6= 100-bp DNA ladder, negative control, sample of conventional corn, MON810, Bt11, and Herculex, respectively. 
Based on the band patterns observed for Bt11 (Figure 3) and MON810 (Figure 4), the presence of these events was detected in the sample with $1 \%$, although for the event MON810, at this level, the presence was detected with a low intensity band pattern.

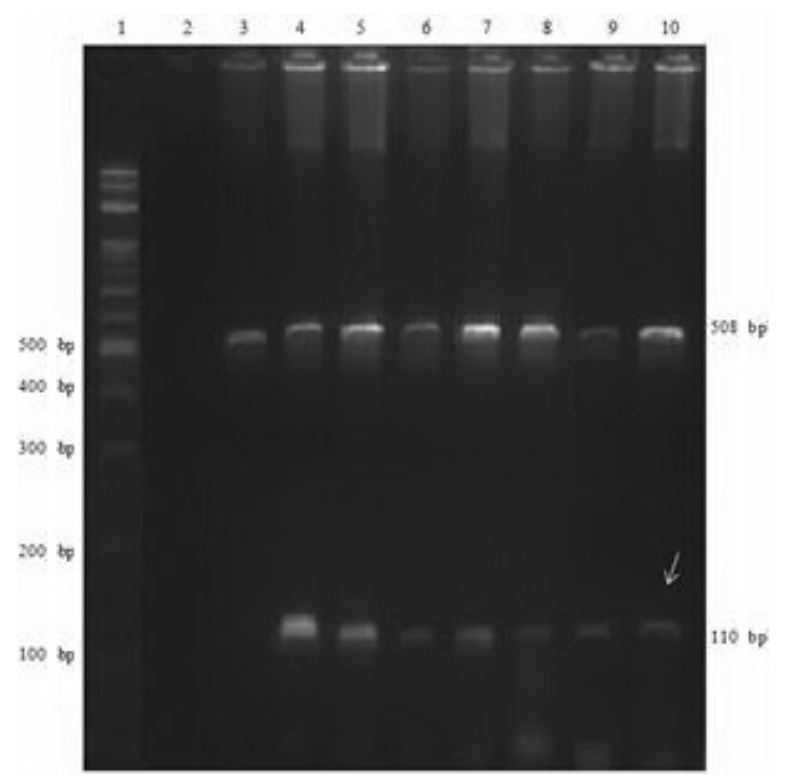

Figure 3. Results of PCR sensitivity for the Bt11 event. Lanes 1-10 = 100-bp DNA ladder, negative control, conventional corn sample, sample of Bt11, and 20,10,5,2, 1, and $0.5 \%$ contamination with genetically modified corn Bt11, respectively.

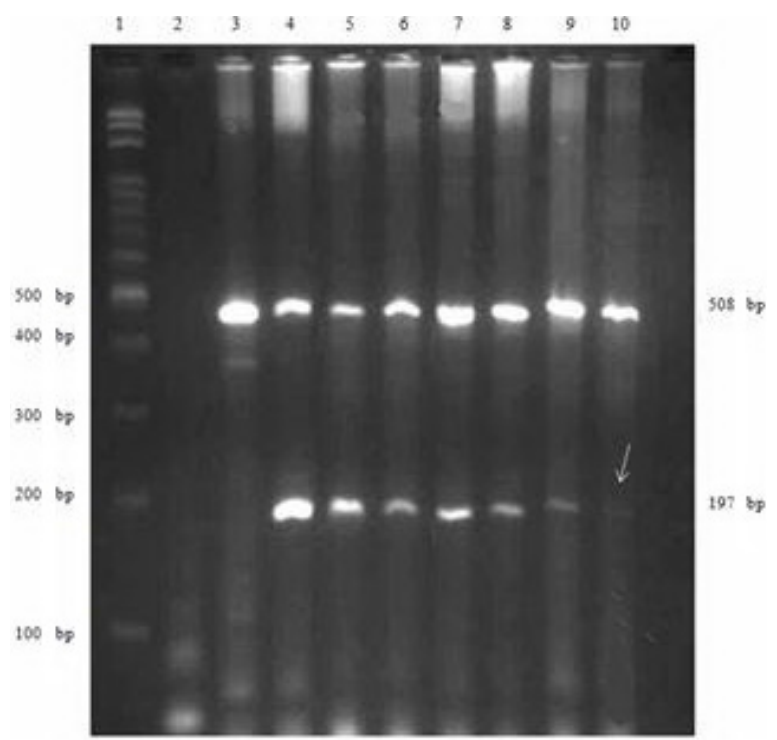

Figure 4. Results of PCR sensitivity for the event MON810. Lanes 1-10=100-bp DNA ladder, negative control, conventional corn sample, sample of corn MON810, and 20, 10, 5, 2, 1, and $0.5 \%$ contamination with genetically modified corn MON810, respectively. 


\section{DISCUSSION}

Tests for the validation and optimization of detection techniques are important for the standardization of available methodologies. According to Ahmed (2002), the factors that affect the optimization and validation of detection techniques of GMOs include the sensitivity of the kits, incubation time, method used, and choice of the detection tolerance limits for qualitative tests, specificity, reproducibility, and reliability of detection.

Huang and Pan (2004) evaluated the efficiency of PCR for the events MON810 and NK603, and achieved a detection limit of $0.5 \%$ for both events. This difference in the results may be attributed to, among other factors, the methodology used in the DNA extraction process and the quality of the DNA extracted, with this being considered the main factor for success in detection of GMOs. The presence of an elevated quantity of impurities associated with the DNA isolated from seeds contributes to reduction in the concentration of the DNA extracted. Seeds are structures of plant multiplication, with a reserve tissue rich in carbohydrates, lipids and proteins. These substances often make the isolation of the DNA difficult, requiring a greater number of washings with the organic solvent, chloroform-isoamyl alcohol. This procedure also leads to reduction in the total quantity of DNA isolated, because part of these molecules does not separate from other organic compounds and is consequently lost.

Another factor to be considered is that normally when using two pairs of primers in the reactions (multiplex PCR) there may be an interaction between the 4 primers, forming dimers and, consequently, resulting in a decrease in PCR efficiency (Huang and Pan, 2004).

Ramos et al. (2006) assessed the sensitivity of the microsatellite technique to detect the presence of corn seeds from other genotypes in lots of corn lines. In that study, the presence of contaminants in the sample with up to $1 \%$ mixture was also detected.

The difference in sensitivity of detection found for the different events may be explained by the levels of expression of these proteins in the seeds. In corn, seed tissues have different levels of ploidy. Thus, this difference may influence the detection of the event, depending on the parental line in which the trait was introduced. Another hypothesis is the construction of the gene cassette in which normally the exogenous DNA is integrated in the genome by chance. Nevertheless, some events already have directed integration of these genes in the plant genome; in other words, the protein is more expressed in the tissue in question.

The detection of genetically modified organisms in some foods, ingredients and additives is necessary for two main reasons. First, many countries, including Brazil, European Union countries, and Japan, believe that consumers may decide whether they want these foods or not, which has led to the adoption of legislation imposing the labeling of foods containing GMOs. Second, in the case of such legislation, it is necessary to implement measures that ensure its enforcement.

By means of the PCR technique, we demonstrated specificity by the differentiation of the events MON810 and Bt11, and sensitivity for detecting contaminations over 1\%, with this being the limit required by Brazilian law for the labeling of foods or food ingredients with genetically modified organisms.

\section{CONCLUSIONS}

Using the PCR technique, it is possible to detect the events Bt11 and MON810 in samples with $1 \%$ contamination. 
In the strip test, the events Bt11 and MON810 are not detected at the levels of 0.4 and $0.8 \%$, as specified by the manufacturer.

The quantity of buffer added to the sample has an influence on the results of the strip test.

\section{ACKNOWLEDGMENTS}

Research supported by Coordenação de Aperfeiçoamento de Pessoal de Nível Superior (CAPES), Conselho Nacional de Desenvolvimento Científico e Tecnológico (CNPq) and Fundação de Amparo à Pesquisa do Estado de Minas Gerais (FAPEMIG).

\section{REFERENCES}

Ahmed FE (2002). Detection of genetically modified organisms in foods. Trends Biotechnol. 20: 215-223.

Huang HY and Pan TM (2004). Detection of genetically modified maize MON810 and NK603 by multiplex and real-time polymerase chain reaction methods. J. Agric. Food Chem. 52: 3264-3268.

International Seed Testing Association (2009). Position Paper on ISTA's View Regarding the Units for the Reporting of Quantitative Results on Presence of Seeds with Specified Traits in Conventional Seed Lots. ISTA GMO Task Force, Document 08-2009, Glattbrugg, 4.

James C (2009). Global Status of Commercialized Biotech/GM Crops. ISAAA Brief No. 41, Ithaca.

Ramos NP, Brunelli KR, Camargo LEA and Filho JM (2006). Sensibilidade dos microssatelites para determinar a pureza varietal em sementes de milho. Rev. Bras. Sementes 28: 99-105. 